\title{
REMOTE SENSING OF LOW VISIBILITY OVER OTOPENI AIRPORT
}

\author{
Livius Buzdugan $^{1,2}$, Denisa Urlea ${ }^{1,2}$, Paul Bugeac ${ }^{1,2}$, Sabina Stefan ${ }^{1}$ \\ ${ }^{1}$ University of Bucharest, Faculty of Physics, P.O.BOX: MG-11, Magurele, Bucharest, Romania \\ (buzdugan.livius@gmail.com) \\ ${ }^{2}$ Romanian Air Traffic Services- ROMATSA, 10 Ion Ionescu De la Brad Str., Bucharest, Romania
}

\begin{abstract}
The paper is focused on the study of atmospheric conditions determining low vertical visibility over Henri Coanda airport. A network of ceilometers and a Sodar were used to detect fog and low level cloud layers. In our study, vertical visibility from ceilometers and acoustic reflectivity from Sodar for November 2016 were used to estimate fog depth and top of fog layers, respectively. The correlation between fog and low cloud occurrence and the wind direction and speed is also investigated.
\end{abstract}

\section{INTRODUCTION}

The prediction of low visibility conditions is of paramount importance for operational weather forecast services. Adverse visibility conditions can strongly reduce the efficiency of a terminal area traffic flow. The application of Low Visibility Procedures (LVP) reduces airport efficiency for takeoffs and landings by a factor of two. Costly delays and flight cancellations ensue [1].

At Bucharest Henri Coanda (OTP) international airport, LVP are applied when visibility is less than $600 \mathrm{~m}(2,000 \mathrm{feet})$ or the ceiling is below 60 $\mathrm{m}$ (200 feet).

The goal of this work is to test how the use of Sodar and CL31 VÄÏSÄLA Ceilometer measurements can help the detection of the top of fog layers which could in turn be used for the initialisation of a high resolution numerical model dedicated to fog forecasting.

The Sodar and Ceilometers are operated at Otopeni Airport close to Bucharest, capital of Romania.

The site, meteorological conditions and the instruments are presented in Section 2.

The capabilities of instruments to detect fog and the link between fog and low cloud occurrence the wind direction and speed are investigated and results are presented in Section3. Section 4 is reserved to conclusions.

\section{METHODOLOGY}

\subsection{Instruments and Measuring Sites}

The geographical and climatological characteristics of the site arise from Henri Coanda airport being situated nearby the city of Bucharest, the largest in Romania with strong urban and plain climatology.

The boundary layer conditions accompanying fog and low cloud are studied using 4 ceilometers and a Sodar installed at Bucharest Henri Coanda airport. The ceilometers are used operationally only to report cloud base height and vertical visibility [3] and to detect and evaluate the fractional extent of cloud layers [3, 5]. They are integrated in the local automated weather observing system (AWOS).

The data used are gathered from the ceilometer and Sodar which are co-located at approximatively $1 \mathrm{~km}$ east of the eastern threshold of one of the runways of Bucharest Henri Coanda airport (44.58N, 26.13E, 92m AMSL). The Ceilometer is installed on the roof of a building formerly hosting a radio-navigation facility, at $4 \mathrm{~m}$ height and owned and operated by ROMATSA (the Romanian Air Traffic Services Administration). The Sodar is also operated by ROMATSA, but owned by INOE (National Institute of Opto-Electronics).

The ceilometer is VÄÏSÄLA CL31 on single-lens technology, 910nm (near-infrared) wavelength, operated with a $10 \mathrm{~m}$ vertical resolution and $15 \mathrm{~s}$ temporal resolution. Its laser diodes are pulsed with a repetition rate of $10 \mathrm{kHz}$ [3]. The ceilometer has been set up for a maximum range of $7700 \mathrm{~m}$ AMSL. It is able to detect three cloud 
layers simultaneously. If the cloud base is obscured due to precipitation or ground-based fog, CL31 reports vertical visibility (VV) [3].

By assuming a linear relationship between backscatter and extinction coefficient and by assuming that the Lidar ratio $(\mathrm{k})$ is constant over the observation range, it is possible to invert the backscatter profile, basically obtaining an extinction coefficient profile which would produce the measured backscatter profile [3].

It has been discovered that in many cases, $\mathrm{k}$ can be assumed to equal 0.03 , tending to be lower (down to to 0.02 ) in high humidity, and higher (up to 0.05 ) in low humidity conditions. However, in precipitation conditions, $\mathrm{k}$ can have a wider range of values [3].

An estimate of vertical visibility can easily be calculated from the extinction coefficient profile because of the straightforward extinction coefficient-to-visibility relationship, assuming a constant contrast threshold. Visibility is simply the height where the integral of the extinction coefficient profile, starting from the ground, equals the natural logarithm of the contrast threshold, sign disregarded [3].

Tests and research have, however, shown that the $5 \%$ contrast threshold widely used in meteorological visibility measurements is unsuitable for vertical visibility measurement [3].

ceilometer CL31 uses a contrast threshold value which has been found to give vertical visibility values closest to those reported by ground-based human observers. A safety margin is obtained with regard to pilots looking down in the same conditions since the contrast between objects, especially runway lights, is much more distinct on the ground [3].

For the purpose of this study, the vertical visibility reported by the ceilometers has been used only to identify the cases with dense, ground-based fog.

The Sodar is a Doppler monostatic METEK PCS 2000-24.

For a Sodar the source of the received signal is the scattering eddy - essentially a density fluctuation - moving along with the air. It can be shown that in monostatic mode the backscattering is due to random temperature fluctuations only [2].
The change in frequency produced by a scatterer (Doppler shift) is proportional to the rate of change of the distance between receiver and scatterer and the initial frequency, so for a known transmitted frequency, a radial velocity corresponding to motions along the beam - can be calculated by measuring the received backscattered wave frequency. Thus the determination of the three-dimensional wind vector requires at least 3 beams with different orientations $[1,4]$.

The METEK PCS 2000-24 Sodar uses a phasedarray antenna consisting of an array of 24 loudspeakers for sequential monostatic soundings of the three-dimensional wind field. The system software controls the operation of each beam. Electronic phase shifters apply a different phase shift to each antenna element to steer the beam. The shifted phase of each element causes the waves to interfere constructively, giving the maximum gain in the desired direction. Five beams are achieved, allowing cross checking among the wind components: [4].

The Sodar was parameterized to a vertical resolution of $20 \mathrm{~m}$ and a first range gate (bottom altitude) of $40 \mathrm{~m}$. The temporal resolution was set to $10 \mathrm{~min}$ (integration time).

\subsection{Data and methods}

In order to find the days with fog and low cloud, the ceilometers measurements for November 2016 have been investigated simultaneously with METAR reports from Bucharest Henri Coanda airport, stored by the local AWOS system. The month of November 2016 was investigated, as several fog situations occurred on the $4^{\text {th }}, 5^{\text {th }}, 12^{\text {th }}$, $19^{\text {th }}$ and $26^{\text {th }}$.

The cloud base heights and vertical visibility from ceilometers measurements were stored and retrieved using the software running on the AWOS operated by ROMATSA. The stored data consist of a text file for each day and parameter (cloud base-heights and vertical visibility) with temporal resolution of $15 \mathrm{~s}$. These data were processed with a software to determine time series of measurements with cloud base within specific intervals and with vertical visibility reported.

It was noticed that dense fog or precipitation is required for the ceilometer to output vertical visibility values instead of cloud base heights. 
Dense fog conditions were declared on site at a time frame when vertical visibility was reported by the ceilometer, only if confirmed by METAR (SPECI) reports or by values of MOR below 1000 meters measured by a nearby transmissometer at $2,5 \mathrm{~m}$ above the ground.

The Sodar reflectivity and wind (direction and speed) profiles were retrieved using the METEK Graphics software, as text files for the whole month, with a temporal resolution of 10 minutes.

An enhanced turbulent activity with temperature fluctuations is expected at the top of the fog layers due to radiative cooling and wind shear and therefore, Sodar reflectivity at the top of a fog layer is expected to exhibit a local maximum [1].

To check this hypothesis, a monthly vertical reflectivity profile was computed by using all the available reflectivity data and compared with a vertical profile of average reflectivity values from time frames with dense fog conditions, as previously defined - covering approximately 12 hours.

Another data set, of low cloud conditions, was defined by measured cloud base heights not higher than 300 meters. The average Sodar reflectivity profile for these conditions - covering approximately 135 hours - was computed.

To investigate if an enhanced turbulence due to increased wind speed, wind shear or an increased vertical thermal gradient was the underlying cause of any Sodar reflectivity maxima, the monthly mean Sodar wind speed and direction profiles and the characteristic wind speed profile for low cloud and fog were also computed.

\section{RESULTS}

In this study, data gathered during November 2016 from a ceilometer co-located with a Sodar at Bucharest Henri Coanda (OTP) airport, were evaluated to test how the use of Sodar measurements can help the detection of the top of fog layers which could in turn be used for the initialisation of a high resolution numerical model dedicated to fog forecasting. The link between fog and low cloud occurrence and the wind direction and speed was also investigated.

In Figure 1, the mean vertical profile of Sodar reflectivity in dense fog situations displays a maximum at heights of 40-100 meters and below and values significantly lower than the general monthly means at heights above 140 meters. This can be explained by the fact that dense fog situations were observed mostly during nighttime hours, with surface temperature inversions generating a significant amount of temperature fluctuations in the inversion layer even at low wind speeds. In Figure 2, the relatively low wind speeds characteristic to the fog events emphasize the decisive role of the temperature inhomogeneities in the increase of reflectivity. A maximum of the Sodar reflectivity clearly positioning the height of the fog layer top is not evident, possibly due to the relatively high value of the lowest range gate $(40 \mathrm{~m})$. Nevertheless, the mean height of the fog top can be traced between 40 and 120 meters, the low values of Sodar reflectivity above 120 meters being explained by the nearly isothermal conditions above the fog top and also by the attenuation of sound in the highly reflective layer below.

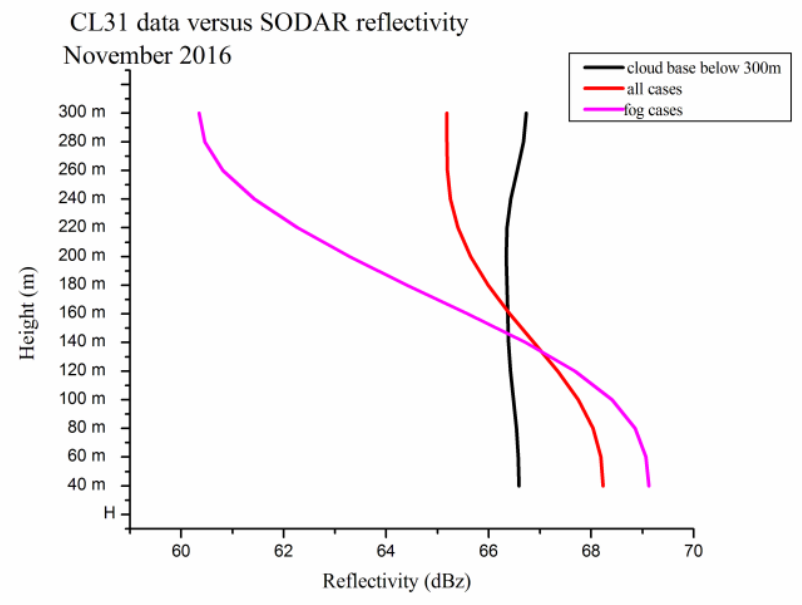

Figure 1. Vertical profiles of mean Sodar reflectivity in low cloud situations as compared to fog situations and monthly average, OTP, November 2016

When compared to the fog situations, the low cloud (base heights not higher than 300 meters, Stratus type cloud) situations exhibit a nearlyconstant vertical profile of Sodar reflectivity up to the maximum cloud base height considered (300 meters). This is consistent with a well-mixed layer and a nearly constant vertical gradient of temperature within the analysed layer.

In Figure 3, the vertical profile of wind speed in the low cloud situations is similar to the monthly mean profile of the wind speed. This leads to the conclusion that the change in the reflectivity 
profile associated with the low clouds exhibited in Figure 1 cannot be accounted for by changes in the wind speed profile - but rather by changes in the temperature profile associated with these clouds, during the analysed period.

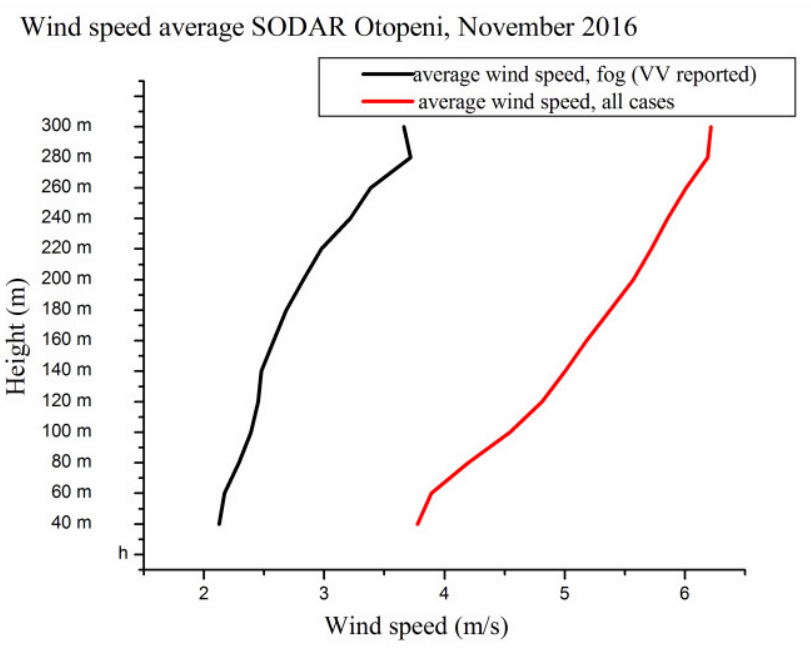

Figure 2. Vertical profiles of wind speed in fog situations as compared to monthly average, OTP, November 2016

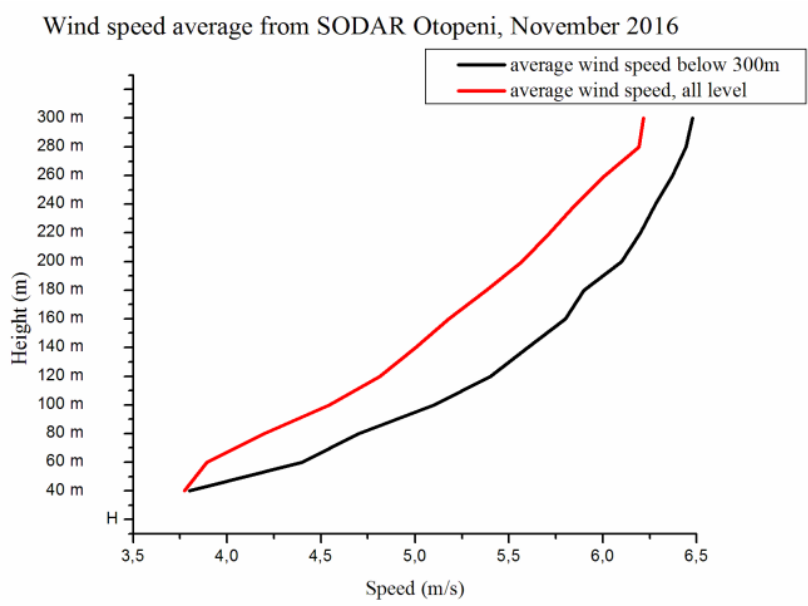

Figure 3. Vertical profiles of wind speed in low cloud situations as compared to monthly average, OTP, November 2016

\section{CONCLUSIONS}

The paper proves that the CL31 ceilometer and a Sodar could be used to provide information on the boundary layer conditions accompanying fog and low cloud and locating the top of the fog layers.

A higher resolution of the Sodar (10 meters) and a lower first range gate could improve the accuracy of the latter determination.

\section{ACKNOWLEDGEMENTS}

The authors gratefully acknowledge ROMATSA for the provision of the data used in this scientific paper.

\section{References}

[1] Dabas, A., Remy, S., Bergot, T (2012) Use of a Sodar to Improve the Forecast of Fogs and Low Clouds on Airports, Pure Appl. Geophys. vol 169, pg. 769781, doi: 10.1007/s00024-011-0334-y

[2] LITTLE, C.G. (1969), Acoustic methods for the remote probing of the lower atmosphere, Proc. IEEE. vol 57, 571-578

[3] VÄÏSÄLA Ceilometer CL31user's guide

[4] PCS.2000-24/64/MF/LP User Manual, METEK Gmbh, 2012

[5] Ungureanu, I. S. Stefan, and D. Nicolae (2010) Investigation of the cloud cover and Planetary Boundary Layer (PBL) characteristics using Ceilometer CL 31. Romanian Reports in Physics, vol 62, nr. 2, pg. 396-404 